\title{
What drives corticospinal output?
}

\section{Roger N Lemon}

Address: UCL Institute of Neurology, Queen Square, London WC1N 3BG, UK

Email: rlemon@ion.ucl.ac.uk

Fl000 Biology Reports 2010, 2:5I (doi:10.34I0/B2-5I)

The electronic version of this article is the complete one and can be found at: http://fl000.com/reports/biology/content/2/5 I

\begin{abstract}
Recent work has not only defined the origin of the direct cortico-motoneuronal output to the upper limb but has also identified some of the cortical networks that engage the corticospinal output during movement. A surprising finding is that some corticospinal neurons show 'mirror-like' properties and are actively modulated not only during self-movement but also during action observation.
\end{abstract}

\section{Introduction and context}

Two central features of corticospinal function are that it reflects the increasingly important role of the expanded neocortex in interactions with the spinal cord and that these interactions mediate not only its traditional role as part of the motor system but also its role in somatosensory, autonomic, developmental, and trophic functions $[1,2]$. All of these functions depend upon a complex interaction between spinal and supraspinal centres. This interaction is present not only in the normal, healthy state but also is seen after damage: injury to the corticospinal tract results in profound changes at both cortical and spinal levels $[3,4]$.

\section{Major recent advances}

Mouse motor cortex studies using powerful optogenetic and other techniques show that a key factor determining the pattern of intracortical connections is the output target of layer $\mathrm{V}$ neurons, including the corticospinal projection. For example, these approaches have shown that projections from layer II/III predominantly innervate the deeper parts of layer $\mathrm{V}$ and differentiate between corticostriatal and corticospinal outputs $[5,6]$. For the first time, we can begin to get some real insights into the intracortical circuitry that computes these different outputs.

It is probable that most corticospinal fibres terminate on spinal interneurons, providing the corticospinal tract with a range of functions, including the filtering afferent input, and modulation of activity in central pattern generators and of reflex excitability $[1,7]$. However, it is unlikely that these interneurons act as a simple relay of corticospinal activity to motoneurons.

A characteristic output of the primate corticospinal system is the direct cortico-motoneuronal (CM) projection, which provides the motor cortex with direct influence over the activity of spinal motoneurons [1]. This CM system is particularly well developed in advanced primates, including humans, but is entirely absent in mice and rats [1]. CM projections were first detected by Leyton and Sherrington $[8,9]$ using silver staining of degenerating terminals after motor cortex lesions. Rathelot and Strick [10,11], using their elegant retrograde transneuronal labelling technique, have for the first time defined the cortical origin of the $\mathrm{CM}$ projection. Most of this projection appears to arise from the caudal region of $\mathrm{M} 1$, in the bank of the central sulcus. These studies have also resolved a long-standing controversy as to whether there is punctuate representation in M1 of outputs to particular muscles, with the argument very much resolved in favor of widespread projections to individual muscles which overlap extensively with those to other muscles. This distributed overlapping organisation is probably essential in providing the combination and recombination of motor outputs required for flexibility in skilled hand control and begins to explain the complex mapping of motor output found both in $\mathrm{M} 1$ and in premotor areas $[12,13]$. 
These studies also highlighted that most CM projections are derived not only from the largest layer $\mathrm{V}$ neurons (the classical Betz cells) but also from corticospinal neurons with much smaller cell bodies. This is an important finding: a complete understanding of corticospinal function must take into account the fact that the vast majority of fibres in the tract are thin, slowly conducting axons.

What are the inputs that recruit corticospinal neurons during skilled hand movements? These neurons receive a sophisticated and complete somatosensory representation of the upper limb and sensory inputs applied to the passive monkey are capable of driving M1 neurons at rates similar to those seen during active movement [14]. The study of transcortical reflexes has now matured into modern ideas about optimal feedback control $[15,16]$.

Visual inputs about objects in our peripersonal space are obviously of major importance for such movements. There are no direct visual inputs to $\mathrm{M} 1$; rather, they are processed through complex pathways involving the posterior parietal cortex and premotor areas [17]. The cortico-cortical interactions with $\mathrm{M} 1$ are dominated by connections with dorsal (PMd) and ventral premotor (PMv) cortices [18]: in monkeys, PMv has been shown to exert powerful excitatory and inhibitory modulation of M1 corticospinal outputs to the hand which are graspspecific $[19]$, and these results have recently been confirmed in human studies with transcranial magnetic stimulation (TMS) [20,21]. The 'visuomotor grasping circuit' [22] provides a means of transforming visual inputs related to an object's properties into outputs from M1 which are appropriate for efficient grasp of the same object.

A novel feature of corticospinal neurons was recently demonstrated by Kraskov and colleagues [23] in the subdivision of PMv which has been termed area F5 [24]. This area is, of course, distinguished by the presence of mirror neurons. First discovered in the 1990s by Rizzolatti and Gallese and their colleagues [25], these fascinating neurons respond during both active grasp and the passive observation of similar actions carried out by another individual. Kraskov et al. [23] found that corticospinal neurons in PMv also showed clear 'mirrorlike' properties, modulating their discharge while the monkey grasped but also when an experimenter grasped. This discovery means that mirror-like activity is also transmitted to the spinal cord and this might explain changes that have been observed in the excitability of both cortex and spinal cord while we observe the actions of others [26]; interestingly, about half of the PMv neurons reported by Kraskov et al. showed suppression of their discharge during action observation, and this might be involved in some way in the inhibition of our own actions (that is, the prevention of unwanted imitation of the actor by the observer). It is important to note that, so far, there is little evidence for direct $\mathrm{CM}$ effects arising from secondary motor areas such as PMv [27] and supplementary motor area [28]. Whether or not CM cells exhibit mirror-like properties is yet to be determined.

During action observation, mirror neuron activity is accompanied by complete absence of any muscle activity in the hand or arm [23]. But if the corticospinal output is important for the generation and execution of voluntary movements when we ourselves move, how is it possible to recruit these neurons in the complete absence of movement when we watch someone else moving? It has long been known that corticospinal activity can be dissociated from electromyography activity [29] and that when movements do follow corticospinal discharge, the delays are typically 80-100 ms, much longer than known physiological delays between cortex and muscle (approximately $10 \mathrm{~ms}$ ). Clearly, corticospinal inputs alone do not recruit spinal motoneurons and must work in parallel with other descending and segmental mechanisms [1].

\section{Future directions}

So we still need to know a lot more about how corticospinal activity is transformed to motor outputs at the spinal level; conjoint recordings at both supraspinal and spinal levels are needed [30,31]; they are extremely challenging but certainly worth the effort. TMS work in humans has shown that there are interesting activity-dependent features of $\mathrm{CM}$ transmission to motoneurons [32] which we have yet to fully understand. We need to get closer to the CM synapse itself. Because of the distinctive nature of the primate versus rodent motor system, much of this work will continue to require the use of non-human primates.

\section{Abbreviations}

$\mathrm{CM}$, cortico-motoneuronal; $\mathrm{PMv}$, ventral premotor cortex; TMS, transcranial magnetic stimulation.

\section{Competing interests}

The author declares that he has no competing interests.

\section{Acknowledgments}

RNL is funded by grants from the Wellcome Trust.

\section{References}

I. Lemon RN: Descending pathways in motor control. Annu Rev Neurosci 2008, 31:195-218. 
2. Chakrabarty S, Martin JH: Postnatal development of a segmental switch enables corticospinal tract transmission to spinal forelimb motor circuits. J Neurosci 2010, 30:2277-88.

3. Bareyre FM, Kerschensteiner M, Raineteau O, Mettenleiter TC, Weinmann $O$, Schwab ME: The injured spinal cord spontaneously forms a new intraspinal circuit in adult rats. Nat Neurosci 2004, 7:269-77.

FI000 Factor 8.2 Exceptional

Evaluated by Corinna Darian-Smith 21 Jul 2004, Clifford J. Woolf 02 Mar 2004, Mark Tuszynski 03 Mar 2004

4. Ghosh A, Haiss F, Sydekum E, Schneider R, Gullo M, Wyss MT, Mueggler T, Baltes C, Rudin M, Weber B, Schwab ME: Rewiring of hindlimb corticospinal neurons after spinal cord injury. Nat Neurosci 2010, 13:97-I04.

5. Anderson CT, Sheets PL, Kiritani T, Shepherd GM: Sublayerspecific microcircuits of corticospinal and corticostriatal neurons in motor cortex. Nat Neurosci 2010, 13:739-44.

6. Brown SP, Hestrin S: Intracortical circuits of pyramidal neurons reflect their long-range axonal targets. Nature 2009, 457: $1133-6$

FI000 Factor 6.0 Must Read

Evaluated by Diego Contreras 27 Mar 2009

7. Grillner S, Wallen P, Saitoh K, Kozlov A, Robertson B: Neural bases of goal-directed locomotion in vertebrates-an overview. Brain Res Rev 2008, 57:2-12.

8. Leyton SSF, Sherrington CS: Observations on the excitable cortex of the chimpanzee, orangutan and gorilla. QJ Exp Physiol 1917, I I:135-222.

9. Lemon RN: An enduring map of the motor cortex. Exp Physiol 2008, 93:798-802.

10. Rathelot JA, Strick PL: Muscle representation in the macaque motor cortex: an anatomical perspective. Proc Natl Acad Sci U S A 2006, 103:8257-62.

FI000 Factor 9.8 Exceptional

Evaluated by Roger Lemon 19 Jun 2006, Cliff Ragsdale 27 Jun 2006,

Corinna Darian-Smith 17 Jul 2006

II. Rathelot JA, Strick PL: Subdivisions of primary motor cortex based on cortico-motoneuronal cells. Proc Natl Acad Sci U S A 2009, 106:918-23.

FI000 Factor 4.8 Must Read

Evaluated by Roger Lemon 30 Jan 2009, Jeffrey Macklis 13 May 2009

12. Boudrias MH, Lee SP, Svojanovsky S, Cheney PD: Forelimb muscle representations and output properties of motor areas in the mesial wall of rhesus macaques. Cereb Cortex 2010, 20:704-19.

13. Boudrias MH, McPherson RL, Frost SB, Cheney PD: Output properties and organization of the forelimb representation of motor areas on the lateral aspect of the hemisphere in rhesus macaques. Cereb Cortex 2010, 20:169-86.

14. Lemon RN: Functional properties of monkey motor cortex neurones receiving afferent input from the hand and fingers. J Physiol (Lond) 198I, 3 I I:497-519.

15. Liu D, Todorov E: Evidence for the flexible sensorimotor strategies predicted by optimal feedback control. J Neurosci 2007, 27:9354-68.

16. Scott $\mathrm{SH}$ : Inconvenient truths about neural processing in primary motor cortex. J Physiol 2008, 586:1217-24.
17. Castiello $U$, Begliomini $C$ : The cortical control of visually guided grasping. Neuroscientist 2008, 14:157-70.

18. Dum RP, Strick PL: Frontal lobe inputs to the digit representations of the motor areas on the lateral surface of the hemisphere. J Neurosci 2005, 25:1375-86.

19. Prabhu G, Shimazu H, Cerri G, Brochier T, Spinks RL, Maier MA, Lemon RN: Modulation of primary motor cortex outputs from ventral premotor cortex during visually-guided grasp in the macaque monkey. J Physiol 2009, 587: 1057-69.

20. Davare M, Lemon R, Olivier E: Selective modulation of interactions between ventral premotor cortex and primary motor cortex during precision grasping in humans. J Physiol 2008, 586:2735-42.

FI000 Factor 3.0 Recommended

Evaluated by Mark Hallett 29 Apr 2008

21. Davare M, Rothwell JC, Lemon RN: Causal connectivity between the human anterior intraparietal area and premotor cortex during grasp. Curr Biol 2010, 20:176-81.

22. Jeannerod M, Arbib MA, Rizzolatti G, Sakata H: Grasping objects: the cortical mechanisms of visuomotor transformation. Trends Neurosci 1995, 18:314-20.

23. Kraskov A, Dancause N, Quallo MM, Shepherd S, Lemon RN: Corticospinal neurons in macaque ventral premotor cortex with mirror properties: a potential mechanism for action suppression? Neuron 2009, 64:922-30.

24. Belmalih A, Borra E, Contini M, Gerbella M, Rozzi S, Luppino G: Multimodal architectonic subdivision of the rostral part (area F5) of the macaque ventral premotor cortex. J Comp Neurol 2009, 5 I 2:183-217.

25. Gallese V, Fadiga L, Fogassi L, Rizzolatti G: Action recognition in the premotor cortex. Brain 1996, I 1 9:593-609.

26. Fadiga L, Fogassi L, Pavesi G, Rizzolatti G: Motor facilitation during action observation: a magnetic stimulation study. J Neurophysiol 1995, 73:2608-II.

27. Shimazu H, Maier MA, Cerri G, Kirkwood PA, Lemon RN: Macaque ventral premotor cortex exerts powerful facilitation of motor cortex outputs to upper limb motoneurones. J Neurosci 2004, 24: 1200-II.

28. Boudrias MH, Belhaj-Saif A, Park MC, Cheney PD: Contrasting properties of motor output from the supplementary motor area and primary motor cortex in rhesus macaques. Cereb Cortex 2006, 16:632-8.

29. Fetz $E E$, Finocchio DV: Operant conditioning of isolated activity in specific muscles and precentral cells. Brain Res 1972, 40:19-24.

30. Riddle CN, Edgley SA, Baker SN: Direct and indirect connections with upper limb motoneurons from the primate reticulospinal tract. J Neurosci 2009, 29:4993-9.

FI000 Factor 3.0 Recommended

Evaluated by Corinna Darian-Smith 27 Apr 2009

3I. Asher I, Zinger N, Yanai Y, Israel Z, Prut Y: Population-based corticospinal interactions in macaques are correlated with visuomotor processing. Cereb Cortex 2010, 20:24I-52.

32. Petersen NC, Butler JE, Taylor JL, Gandevia SC: Probing the corticospinal link between the motor cortex and motoneurones: some neglected aspects of human motor cortical function. Acta Physiol (Oxf) 2010, 198:403-16. 